\title{
ANALISIS FAKTOR YANG MEMPENGARUHI PENGEMBANGAN POSYANDU LANSIA DI SIDOARJO
}

\author{
Sri Mukhodim Faridah $\mathbf{H}^{\text {1)}}$, Hesty Widowati ${ }^{2)}$ Agus Salim $^{3)}$ \\ ${ }^{1,2}$ Program Studi Pendidikan Profesi Bidan FIKES Universitas Muhammadiyah Sidoarjo \\ ${ }^{3}$ Program Studi SI Paud Fakultas PIP Universitas Muhammadiyah Sidoarjo \\ email: ${ }^{1}$ srimukhodimfaridahhanum@umsida.ac.id, 2agussalim@umsida.ac.id
}

\begin{abstract}
Abstrak
Posyandu lansia adalah pos pelayanan terpadu untuk masyarakat lansia yang telah di gerakkan oleh masyarakat. Keberhasilan kegiatan posyandu lansia menurut Dinas Kesehatan Sidoarjo apabila mencakup minimal $70 \%$ dari populasi lansia lansia yang berusia 45-60 tahun keatas.Tahun 2018 cakupan pelayanan lansia masih 49,5\%, dari data tersebut Sidoarjo masih rendah dari target keberhasilan. Metode penelitian survey analitik menggunakan data primer dengan kuisioner Pada 30 kader posyandu dan tokoh masyarakat di Perum Griya Bhayankara Permai Urangagung dan desa Panambangan Balongbendo Kabupaten Sidoarjo. Analisis dengan menggunakan uji Bivariant eksak fisher test untuk mendapatkan faktor yang merpengaruhi pengembangan posyandu. Hasil penelitian menunjukkan factor motivasi kader yang mempengaruhi pengembangan posyandu lansia di Sidoarjo dengan nilai $P=0,00$ sedangkan factor pendidikan kader dan tokoh masyarakat nilai $P>0,05$ artinya tidak ada pengaruh pendidikan kader dan tokoh masyarakat dengan dpengembangan Posyandu Lansia. Sedangkan dukungan tenaga kesehatan dari hasil analisis deskriptif juga tidak ada perubahan yang signifikan. Di sarankan untuk penelitian selanjutnya menanalisis factor lain yang terkait dengan pemangku kepentingan.
\end{abstract}

Kata kunci : Pengembangan Posyandu Lansia, kader posyandu dan tokoh masyarakat.

\begin{abstract}
Elderly Posyandu is an integrated service post for the elderly community that has been moved by the community. The success of the elderly posyandu activities according to the Sidoarjo Health Service if it covers a minimum of 70\% of the elderly elderly population aged 45-60 years and over. In 2018 elderly service coverage is still 49.5\%, from these data Sidoarjo is still low from the target of success. The analytical survey research design uses primary data with questionnaires at 30 posyandu cadres and community leaders at Bhayankara Permai Urangagung Griya Perum and Balongbendo Panambangan village, Sidoarjo Regency. The analysis used the Bivariant exak fishertest to obtain factors that influenced the development of posyandu.The results showed the motivation factor of cadres that influenced the development of the elderly posyandu in Sidoarjo with a $P$ value of 0.00 while the educational factors of cadres and community leaders were $P>0.05$ meaning there was no influence of education of cadres and community leaders with the development of Posyandu Elderly. while the support of health personnel from the results of the descriptive analysis also had no significant changes. It is suggested that further research analyzes other factors related to stakeholders.
\end{abstract}

Keywords: Development of Elderly Posyandu, Posyandu cadres and community leaders 


\section{PENDAHULUAN}

Peningkatan angka usia harapan hidup merupakan salah satu indikator keberhasilan perbaikan kualitas kesehatan dan kondisi sosial masyarakat indonesia (Kemenkes RI, 2017). Hasil sensus penduduk yang dilakukan oleh BPS pada tahun 2016 menunjukkan bahwa penduduk indonesia memiliki angka harapan hidup hingga 71,7 tahun. Angka ini jauh lebih baik dari angka harapan hidup masyarakat indonesia tiga dekade sebelumnya, yaitu di bawah 60 tahun (BPS, 2016). Semakin maju suatu negara, semakin banyak penduduknya yang mencapai lanjut usia. Kemajuan di berbagai bidang kehidupan termasuk bidang kesehatan dan ekonomi dipercaya merupakan salah satu penyebab meningkatnya usia minati masyarakat salah satunya kurang adanya pengembangan sehingga tidak menarik kegiatan yang monoton ( hennywati,2008).

Hal ini dapat di sebabkan dari factor kader dan tokoh masyarakat yang ada antara lain sikap, pengetahuan, umur, pendidikan, motivasi, dukungan pemangku kebijakan dan petugas kesehatan (Susanti N, 2011) Data pada posyandu lansia di Perum Griya Bhayangkara Permai Rw 09, Ds UrangagungSidoarjo pada tahun 2017 dari 215 lansia (100\%) yang didapatkan hanya 30 lansia (14\%) yang memanfaatkan adanya posyandu lansia, sedangkan sisanya 185 lansia (86\%) tidak memanfaatkan adanya posyandu lansia dengan alasan tidak ada yang mengantar, tidak tahu dan malas karena kegiatannya hanya cek kesehatan saja. Berdasarkan data yang didapatkan menunjukan bahwa rendahnya angka pemanfaatan posyandu lansia di Perum Griya Bhayangkara Permai Rw 09, Ds Urangagung-Sidoarjo dibandingkan dengan target di kabupaten sidoarjo yaitu $70 \%$.

Keberhasilan kegiatan posyandu lansia menurut Dinas Kesehatan Sidoarjo apabila mencakup minimal $70 \%$ dari populasi lansia lansia yang berusia 45-60 tahun keatas. Tahun 2018 cakupan pelayanan lansia masih 49,5 \%, dari data tersebut Sidoarjo masih rendah dari target keberhasilan harapan hidup pada lansia (Kemenkes RI, 2017). Kegiatan posyandu lansia yang berjalan dengan baik akan memberi kemudahan bagi lansia untuk mendapatkan pelayanan kesehatan dasar, sehingga kualitas hidup masyarakat lansia tetap terjaga dengan baik dan optimal

(Erpandi,2014). Berbagai kegiatan dan program posyandu lansia tersebut sangat baik dan banyak memberikan manfaat bagi lansia di wilayahnya. Seharusnya para lansia berupaya memanfaatkan adanya posyandu tersebut sebaik mungkin, agar kesehatan para lansia dapat terpelihara dan terpantau secara optimal (Ningsih et all, 2014).

Beberapa faktor yang dapat mempengaruhi posyandu lansia kurang di minati masyarakat salah satunya kurang adanya pengembangan sehingga tidak menarik kegiatan yang monoton ( hennywati,2008). Hal ini dapat di sebabkan dari factor kader dan tokoh masyarakat yang ada antara lain sikap, pengetahuan, umur, pendidikan, motivasi, dukungan pemangku kebijakan dan petugas kesehatan (Susanti N, 2011).

Data pada posyandu lansia di Perum Griya Bhayangkara Permai Rw 09, Ds Urangagung-Sidoarjo pada tahun 2017 dari 215 lansia (100\%) yang didapatkan hanya 30 lansia (14\%) yang memanfaatkan adanya posyandu lansia, sedangkan sisanya 185 lansia (86\%) tidak memanfaatkan adanya posyandu lansia dengan alasan tidak ada yang mengantar, tidak tahu dan malas karena kegiatannya hanya cek kesehatan saja. Berdasarkan data yang didapatkan menunjukan bahwa rendahnya angka pemanfaatan posyandu lansia di Perum Griya 
Bhayangkara Permai Rw 09, Ds UrangagungSidoarjo dibandingkan dengan target di kabupaten sidoarjo yaitu 70\%.. Keberhasilan kegiatan posyandu lansia menurut Dinas Kesehatan Sidoarjo apabila mencakup minimal $70 \%$ dari populasi lansia lansia yang berusia 45-60 tahun keatas.Tahun 2018 cakupan pelayanan lansia masih $49,5 \%$, dari data tersebut Sidoarjo masih rendah dari target keberhasilan.

\section{METODE PENELITIAN}

Desain peneltian analitik dengan pendekatan cross sectional dengan menggunakan uji statistiktik bivariant eksak fiser test untuk mengetahui adanya hubungan variable pendidikan dan motivasi kader dengan pengembangan posyandu lansia, sementara variable dukungan tenaga kesehatan tidak dapat di uji statistic karena data constan sehingga analisis dengan deskriptif table silang. Populasi dalam penelitian ini adalah kader posyandu lansia di desa Penambangan kecamatan balong bendo dan kader posyandu lansia di perum bahayangkara permai Urangagung Sidoarjo berjumlah 33 orang . Sampel dalam penelitian ini berjumlah 30 orang kader dengan menggunakan rumus sampel terdiri dari kader posyandu 25 dan tokoh masyrakat 5 orang. Pengumpulan data yang digunakan pada variable pendidikan, motivasi kader, dukungan tenaga kesehatan dan pengembangan posyandu lansia menggunakan kuesioner yang di isi oleh kader posyandu dan tokoh masyarakat pada saat kegiatan posyandu lansia.

\section{HASIL DAN PEMBAHASAN}

A. Hubungan pendidikan kader dengan pengembangan posyandu Lansia

\section{Tabel 1}

Tingkat Pendidikan dengan Pengembangan Posyandu Lansia

\begin{tabular}{|c|c|c|c|}
\hline \multirow{3}{*}{$\begin{array}{l}\text { Jenis } \\
\text { Pendidikan }\end{array}$} & \multicolumn{2}{|c|}{ Pengembangan } & \multirow{3}{*}{ Jumlah } \\
\hline & \multicolumn{2}{|c|}{ Posyandu } & \\
\hline & Cukup & Baik & \\
\hline \multirow{4}{*}{ SD - SMP } & 1 & $0(0 \%)$ & $1(100 \%)$ \\
\hline & $(10$ & & \\
\hline & $0 \%$ & & \\
\hline & ) & & \\
\hline \multirow[t]{2}{*}{ SMA } & $8(29 \%)$ & $20(71 \%$ & $28(100 \%)$ \\
\hline & & ) & \\
\hline \multirow[t]{2}{*}{ PT } & $1(100 \%)$ & & $1(100 \%)$ \\
\hline & & $0(0 \%)$ & \\
\hline Total & 10 & 20 & 30 \\
\hline
\end{tabular}

Berdasarkan Tabel 1 menunjukkan bahwa hampir seluruhnya $(93,4 \%)$ kader posyandu lansia berpendidikan SMA.Hasil Uji Statistik : nilai $\mathrm{P}=103(\mathrm{P}>0,05)$ artinya tidak ada hubungan antara motivasi kader dan tokoh masyarakat dengan pengembangan posyandu lansia.

Tabel 2

Motivasi Kader dengan Pengembangan Posyandu Lansia

\begin{tabular}{|c|c|c|c|}
\hline \multirow{2}{*}{$\begin{array}{l}\text { Motivasi } \\
\text { Kader }\end{array}$} & \multicolumn{2}{|c|}{$\begin{array}{l}\text { Pengembangan } \\
\text { Posyandu }\end{array}$} & \multirow{2}{*}{ Jumlah } \\
\hline & Cukup & Baik & \\
\hline Kurang & $1(100 \%)$ & $0(0 \%)$ & $1(100 \%)$ \\
\hline Cukup & $5(100 \%)$ & $0(0 \%)$ & 5 \\
\hline \multirow[t]{2}{*}{ Baik } & $4(17 \%)$ & $20(83 \%)$ & $(100 \%)$ \\
\hline & & & $\begin{array}{l}24 \\
(100 \%)\end{array}$ \\
\hline Total & 10 & 20 & 30 \\
\hline
\end{tabular}

Berdasarkan Tabel 2. Menunjukkan bahwa hampir seluruh responden yang mempunyai motivasi baik ( $80 \%$ ) terdapat 
pada pengembangan posyandu yang baik.Hasil Uji Statistik : nilai $\mathrm{P}=0,000(\mathrm{P}<$ $0,05)$ artinya ada hubungan antara motivasi kader dan tokoh masyarakat dengan pengembangan posyandu lansia.

\section{Tabel 3}

Dukungan Petugas Kesehatan dengan Pengembangan Posyandu Lansia

\begin{tabular}{lccc}
\hline Dukunga & \multicolumn{2}{c}{$\begin{array}{c}\text { Pengembangan } \\
\text { n Petugas }\end{array}$} & \multicolumn{2}{c}{ Jumlah } \\
Kesehata & Posyandu & \\
$n$ & Cukup & Baik & \\
Kurang & $0(0 \%)$ & $0(0 \%)$ & $0(0 \%)$ \\
\hline Cukup & $0(0 \%)$ & $0(0 \%)$ & $0(0 \%)$ \\
\hline Baik & $10(33,3 \%$ & $20(66,7 \%$ & $30(100 \%$ \\
& ) & ) & ) \\
\hline Total & $\mathbf{1 0}$ & $\mathbf{2 0}$ & $\mathbf{3 0}$ \\
\hline
\end{tabular}

Berdasarkan Tabel 3. menunjukkan bahwa sebagian besar $(66,7 \%)$ dukungan petugas kesehatan dalam pelayanan posyandu lansia adalah baik terdapat pada pengembangan posyandu lansia yang baik Hasil Uji Statistik : Tidak dapat di uji statistic karena data Dukungan tenaga kesehatan constant sehingga analisis menggunakan deskriptif table silang.

\section{Hubungan pendidikan kader dan tokoh masyarakat dengan pengembangan posyandu Lansia}

Dari hasil uji statistic yang di lakukan menunjukkan tidak adanya hubungan yang signifikan antara pendidikan kader dan tokoh masyarakat dengan pengembangan posyandu Lansia. Berdasarkan Tabel 1 didapatkan Pendidikan kader dan tokoh masyarakat tidak berbeda dalam pengaruhnya terhadap pengembangan posyandu lansia di Sidoarjo baik yang pendidikannya SD, SMP, SMA maupun Perguruan tinggi.
Sedngkan menurut Aldriana (2016) beberapa faktor yang dapat mempengaruhi posyandu lansia kurang di minati masyarakat salah satunya kurang adanya pengembangan sehingga tidak menarik kegiatan yang monoton Hal ini dapat di sebabkan dari faktor kader dan tokoh masyarakat yang ada antara lain sikap, pengetahuan, umur, pendidikan, motivasi, dukungan pemangku kebijakan dan petugas kesehatan. .Dalam peneltian ini pendidikan bukan satu-satunya factor yang mempengaruhi. pengembangan posyandu lansia.

\section{Hubungan Motivasi Kader dengan Pengembangan Posyandu Lansia \\ Dari hasil uji statistic yang di} lakukan menunjukkan adanya hubungan yang signifikan antara motivasi kader dan tokoh masyarakat dengan pengembangan posyandu Lansia Berdasarkan tabel 2 didapatkan pada motivasi kader dan tokoh masyarakat yang baik maka pengembangan posyandu lansia juga menjadi baik . Bila kader tidak memberikan informasi kepada para lansia maka para lansia tidak akan memanfaatkan pelayanan posyandu lansia. Seorang kader selain mempunyai tugas dan fungsi juga harus mampu berkomunikasi dengan baik dan mampu mengajak dan memotivasi para lansia. Seorang kader juga harus dapat membina semua yang terkait dengan pelaksanaan posyandu, tetapi juga harus memantau pertumbuhan perkembangan lansia (Kemenkes RI,2014).Untuk meningkatkan citra diri seorang kader maka harus memperhatikan dan meningkatkan kualitas diri sebagai seorang kader. Selain itu diharapkan sebagai seorang kader bersama keluarganya supaya memotivasi lansia untuk memanfaatkan pelayanan posyandu lansia (Susanti, 2011). 


\section{Dukungan Petugas Kesehatan dengan Pengembangan Posyandu Lansia}

Hasil tabulasi silang dengan analisis deskriptif menunjukkan bahwa seluruh dukungan tenaga kesehatan adalah pada kategori baik, dukungan baik ini pada pengembangan posyandu yang dengan kriteria baik $(66,7 \%)$ maupun cukup $(33,3 \%)$ artinya tidak berpengaruh antara dukungan tenaga kesehatan dengan pengembangan posyandu lansia. Peranan petugas kesehatan mempuyai hubungan yang kuat terhadap perilaku masyarakat dalam pemanfaatan pelayanan kesehatan maupun sebagai petugas dalam pelayanan di masyarakat. Perilaku responden yang baik dalam memanfaatkan pelayanaan kesehatan sangat diperlukan adanya petugas kesehatan secara terus menerus dan berkesinambungan dalam melakukan pendekatan dan memberikan informasi kesehatan kepada masyarakat lansia (Susanti N, 2011). Namun dalam pengembangan posyandu lansia ada beberapa factor yang mempengaruhinya antara lain dari factor kader dan tokoh masyarakat yang ada antara lain sikap, pengetahuan, umur, pendidikan, motivasi, dukungan pemangku kebijakan.

\section{KESIMPULAN}

Kesimpulan dalam penelitian ini adalah adanya pengaruh motivasi kader dengan pengembangan posyandu lansia di Sidoarjo dan tidak ada pengaruh pendidikan kader dan tokoh masyarakat dan dukungan tenaga kesehatan dengan pengembangan posyandu lansia di Sidoarjo., disarankan untuk penelitian selanjutnya menanalisis faktor lain yang terkait dengan pemangku kepentingan.

\section{REFERENSI}

Aldriana, N. 2016. Faktor-Faktor Yang Berhubungan Dengan Rendahnya Kunjungan Lansia Ke Posyandu Lansia Di Desa Rambah Tengah Utara Wilayah Kerja Puskesmas Rambah Tahun 2015. journal.upp.ac.id/index.php/akbd/ article/download/1080/781

Badan Pusat Statistik, 2016. Statistik Penduduk Lanjut Usia 2016. Jakarta : Badan Pusat Statistik.

Dinkes. 2016. Buku Pedoman Telaah Kemandirian UKBM (3rd ed.). jawa timur: Dinas Kesehatan Provinsi Jawa Timur.

Erpandi. 2014. Posyandu Lansia: Mewujudkan Lansia Sehat, Mandiri, dan Produktif. Jakarta: EGC.

Susanti N,Mitra, 2011. Faktor yang berhubungan dengan pemanfaatan posyandu Lansia,E-Jurnal kesehatan komunitas.Vol 1 No 3. November 2011.

Kemenkes R1. 2017. Pusat Data Dan Informasi : Situasi Dan Analisis Lanjut Usia.

Kemenkes R1. 2014. Pusat Data Dan Informasi : Gambaran Kesehatan Lanjut Usia di Indonesia.

Lestari, T. 2015. Kumpulan Teori Untuk Kajian Pustaka Penelitian Kesehatan. Yogyakarta: Nuha Medika.

Ningsih, Rahmalia., Arneliwati., \& Lestari, Widia. 2014. Faktor-Faktor Yang Mempengaruhi Minat Lansia Mengunjungi Posyandu Lansia. Universitas Riau. Di kutip dari https://media.neliti.com/media/publicat ions/183825-ID-faktor-faktor-yangmempengaruhi-minat-la.pdf 